\title{
Article
}

\section{Semi-Batch Gasification of Refuse-Derived Fuel (RDF)}

\author{
Juma Haydary ${ }^{1, *(\mathbb{D})}$, Patrik Šuhaj ${ }^{1}$ and Michal Šoral ${ }^{2}$ (]) \\ 1 Institute of Chemical and Environmental Engineering, Faculty of Chemical and Food Technology, \\ Slovak University of Technology in Bratislava, Radlinského 9, SK-812 37 Bratislava, Slovakia; \\ patrik.suhaj@stuba.sk \\ 2 Analytical Department, Institute of Chemistry, Slovak Academy of Sciences, Dúbravská cesta 9, \\ SK-845 38 Bratislava, Slovakia; michal.soral@savba.sk \\ * Correspondence: juma.haydary@stuba.sk
}

\section{check for} updates

Citation: Haydary, J.; Šuhaj, P.; Šoral, M. Semi-Batch Gasification of Refuse-Derived Fuel (RDF). Processes 2021, 9, 343. https://doi.org/ $10.3390 /$ pr9020343

Academic Editor: Albert Ratner

Received: 26 January 2021

Accepted: 9 February 2021

Published: 13 February 2021

Publisher's Note: MDPI stays neutral with regard to jurisdictional claims in published maps and institutional affiliations.

Copyright: (C) 2021 by the authors Licensee MDPI, Basel, Switzerland. This article is an open access article distributed under the terms and conditions of the Creative Commons Attribution (CC BY) license (https:/ / creativecommons.org/licenses/by/ $4.0 /)$.

\begin{abstract}
Gasification is a promising technology for the conversion of mixed solid waste like refusederived fuel (RDF) and municipal solid waste (MSW) into a valuable gas consisting of $\mathrm{H}_{2}, \mathrm{CO}$, $\mathrm{CH}_{4}$ and $\mathrm{CO}_{2}$. This work aims to identify the basic challenges of a single-stage batch gasification system related to tar and wax content in the producer gas. RDF was first gasified in a simple semi-batch laboratory-scale gasification reactor. A significant yield of tars and waxes was received in the produced gas. Waxes were analyzed using gas chromatography-mass spectrometry (GCMS) and nuclear magnetic resonance (NMR) spectrometry. These analyses indicated the presence of polyethylene and polypropylene chains. The maximum content of $\mathrm{H}_{2}$ and $\mathrm{CO}$ was measured 500 seconds after the start of the process. In a second series of experiments, a secondary catalytic stage with an $\mathrm{Ni}$-doped clay catalyst was installed. In the two-stage catalytic process, no waxes were captured in isopropanol and the total tar content decreased by approximately $90 \%$. A single one-stage semi-batch gasification system is not suitable for RDF gasification; a large fraction of tar and waxes can be generated which can cause fouling in downstream processes. A secondary catalytic stage can significantly reduce the tar content in gas.
\end{abstract}

Keywords: gasification; RDF; MSW; tar; wax

\section{Introduction}

Based on the EU directive 2018/850 on the landfill of waste [1], member states are obliged to reduce the yield of municipal waste landfilled to less than $10 \%$ by 2035 . Currently, many countries, including Slovakia, send more than 50\% of MSW to landfills. Reaching EU targets in MSW landfilling requires the intensive implementation of alternative recycling and recovery technologies. Thermochemical conversion is a promising method of solid waste conversion, including heterogeneous mixed waste like MSW, into valuable materials and energy [2].

Refuse-Derived Fuel (RDF) is produced from municipal solid waste (MSW) by the separation of incombustibles and often also biologically degradable fractions. The main components of RDF are plastic fraction (low density polyethylene-LDPE, high density polyethylene-HDPE, polypropylene-PP, polyethylene terephthalate-PET, polystyrene and other synthetic polymers), paper fraction (white paper, colored papers, cardboards, soft paper, etc.), textile fraction (natural and synthetic fibers), and other organic materials such as wood, rubber etc. [3].

Gasification of this waste produces gases consisting mainly of $\mathrm{H}_{2}, \mathrm{CO}, \mathrm{CH}_{4}$ and $\mathrm{CO}_{2}$. However, this gas can contain many impurities such as solid particles, tars, compounds of sulfur, chlorine, etc. [4]. Although much attention has been devoted to gasification in recent years, there are still a number of challenges to the full commercialization of waste gasification [5]. To be used in internal combustion engines, turbines or in methanol or ammonia processes, the gas should meet relatively strict requirements for gas composition, heating value, tar content and sulfur and chlorine content [6,7]. 
The quality of the gas is significantly affected by the gasification technology used and the conditions in the gasifier. Moving bed gasifiers [8], fluidized bed gasifiers [9] and entrained flow gasifiers [10] commercialized and used in coal gasification have been employed also in the gasification of biomass and waste [11,12]. Although large industrialscale gasification is usually carried out in continuous mode, many small or pilot scale gasifiers were designed for batch or semi-batch modes. In a semi-batch gasification system, the gas phase is continuously removed from the reactor and usually a carrier gas is flowing into the reactor. The conditions of fixed-bed, or better called, moving-bed gasifiers are very similar to batch gasifiers and many challenges in batch gasification systems can be expected also in fixed-bed gasifiers.

The high tar content of gas is one of the most important disadvantages of fixed-bed and semi-batch gasifiers. In updraft gasifiers, the yield of tar typically reaches values up to $100 \mathrm{~g} / \mathrm{Nm}^{3}$ [13] $\left(101.325 \mathrm{kPa}, 0^{\circ} \mathrm{C}\right)$. The yield and characteristics of tars depend also on the feed composition. Yu et al. [14] reported characteristics of tar formation during cellulose, hemicellulose and lignin gasification. They found different compositions of tars received from these materials; however, polycyclic aromatic hydrocarbons (PAHs) were the dominant components in all cases. Benzene, toluene, ethylbenzene, xylene (BTEX), phenols and oxygenated hydrocarbons were other types of components found. However, as reported by Li and Suzuki [15], the characteristics of tars from biomass gasification depend also on the gasification temperature. At $400{ }^{\circ} \mathrm{C}$, mixed oxygenates are the dominant type of tar components; at $500{ }^{\circ} \mathrm{C}$, phenolic ethers; at $600{ }^{\circ} \mathrm{C}$, alkyl phenolics; at $700{ }^{\circ} \mathrm{C}$, heterocyclic ethers; at $800{ }^{\circ} \mathrm{C}, \mathrm{PAHs}$; and at $900{ }^{\circ} \mathrm{C}$, larger PAHs. In the case of plastic wastes, primary tars are alkanes and alkenes or aromatics if the gasified polymers contain aromatic rings. Linear hydrocarbons are not thermally stable; they are cracked at higher gasification temperatures and secondary (aromatics, alkyl aromatics, phenols) and tertiary (PAHs) tars are created $[16,17]$. RDF is a mixture of natural polymers (cellulose, hemicellulose, lignin ... ) and synthetic polymers such as polyethylene (PE), polypropylene (PP), polystyrene (PS), polyethylene terephthalate (PET), polyamide (PA), etc. Based on this composition, mixed characteristics of tars from lignocellulosic biomass and from plastic waste can be expected. However, reactions between primary tars from different resources can result in a synergic effect. For example, $\mathrm{C}_{2}-\mathrm{C}_{4}$ olefins can act as tar precursors and promote tar formation reactions [16].

Reports on the presence of waxes in producer gas from MSW or RDF gasification were not found in the open literature. However, many pilot- and laboratory-scale units with updraft fixed bed or semi-batch reactors where MSW or RDF was used as feedstock reported pipes plugging because of the high tar and wax content in the gas. However, waxes were reported as the pyrolysis product of MSW, RDF and plastics. In some cases, up to $93 \%$ of the product yields were created by light and heavy waxes [18]. Buah et al. [19] pyrolyzed RDF at 400 to $700{ }^{\circ} \mathrm{C}$ and measured an oil/wax yield from 30 to $50 \mathrm{wt} . \%$. Selectivity to waxes depends on the pyrolysis technology used. Waxes as segments of polyolefin chains are the primary pyrolysis product of polyolefins; the short reaction time and rapid cooling of pyrolysis vapors increase their yield. Arabiourrutia et al. [20] reported the characteristics of waxes from the pyrolysis of three different polyolefin plastics (HDPE, LDPE and PP) in a conical-spouted bed reactor, the yield of waxes varied between 50 and $92 \%$ with the highest yield for PP; the authors found that $90 \%$ of waxes were collected as white powder in the filter downstream of the reactor, the melting point of waxes was between 60 and $95^{\circ} \mathrm{C}$.

Taking into account the wax formation during the pyrolysis of plastics and considerable amounts of plastics in MSW and RDF, it can be assumed that high tar and wax yields in pilot-scale gasification units can be related to no appropriate gasification technology and process conditions used. In contrast to fast pyrolysis of plastics when tar and waxes are usually desired products, they are undesired and have to be removed from the producer gas in the gasification process. Tar and wax yields can be influenced by the gasification technology used and process conditions like temperature, residence time or oxygen flow [21]. 
Further reduction of tar can be achieved by physical or chemical ex-situ methods such as scrubbing or secondary catalytic cracking. A detailed discussion of the secondary catalytic cracking of tars is presented in previous works [22-24].

This work aims to identify the basic challenges of a single-stage semi-batch gasification system related to tar and wax content in the producer gas. A more detailed characterization of the tar and wax yield is provided. The effect of process parameters such as temperature and residence time on product yields and gas composition is observed. A secondary catalytic stage using cheap catalysts was tested and results were compared with those of the one-stage batch gasification system.

\section{Materials and Methods}

\subsection{RDF Characterization}

The RDF used in this work was obtained from a waste recycling company in Slovakia. The company produces RDF from municipal solid waste by the separation of inorganics and biodegradables. A plastic rich fraction coming from industrial waste was used to control the RDF heating value within a required range. The company produces RDF for use in cement kilns. The obtained RDF was characterized by thermogravimetric analysis, elemental analysis, calorimetric analysis and differential scanning calorimetry. Samples for RDF characterization were homogenized by grounding of around $2 \mathrm{~kg}$ of the waste to particles of sizes lower than $1 \mathrm{~mm}$. Then, $200 \mathrm{~g}$ of RDF were ground to powder in a cryogenic mill. However, some waste components remained in the form of small-sized fibers or particles. Therefore, all measurements of RDF characterization were carried out at least in triplicate to obtain average values with a relative deviation lower than $10 \%$.

For thermogravimetric analysis, a simultaneous TG/DSC thermal analyzer (STA 409 PC Luxx ${ }^{\circledR}$ from NETZSCH, Selb, Germany) was used. In this work, TG measurements were performed with a dual purpose: to determine the approximate analysis (moisture, volatile matter, fixed carbon and ash content), and to monitor the behavior of RDF thermal decomposition. The samples were heated from room temperature up to $800{ }^{\circ} \mathrm{C}$ in an inert atmosphere (nitrogen) at a heating rate of $10 \mathrm{~K} \mathrm{~min}^{-1}$. Measurements continued in an inert atmosphere at $800^{\circ} \mathrm{C}$ for $30 \mathrm{~min}$. After this period, oxygen was introduced to the system and the sample was combusted at $800{ }^{\circ} \mathrm{C}$. The inert gas flow rate was $120 \mathrm{ml} \mathrm{min}{ }^{-1}$. The used oxygen flow rate for sample combustion was $60 \mathrm{ml} \mathrm{min}^{-1}$.

Elemental analysis was performed using an elemental analyzer (Vario Macro Cube ELEMENTAR, Elementar Analysensystem, GmbH, Langenselbold, Germany). The content of carbon, hydrogen, nitrogen and sulfur was obtained using a CHNS module with the combustion tube temperature at $1150^{\circ} \mathrm{C}$ and the reduction tube temperature at $850{ }^{\circ} \mathrm{C}$. The content of chlorine was obtained using a $\mathrm{Cl} 5000 \mathrm{ppm}$ detector (Elementar Analysensystem, $\mathrm{GmbH}$, Langenselbold, Germany). The content of oxygen was estimated by calculation to $100 \%$. The higher heating value (HHV) of RDF was measured using an FTT isoperibolic calorimetric bomb (Fire Testing Technology Ltd., East Grinstead, UK). Combustion of the sample took place in a calorimetric bomb under an oxygen atmosphere at 30 bar. Benzoic acid was used as a standard material.

\subsection{RDF Gasification Experiments}

Initially, a single-stage laboratory-scale batch gasification system (Figure 1a) was used to observe the effect of temperature and residence time on tar and wax content in the producer gas. A 20 gram sample of RDF with a particle size lower than $1 \mathrm{~mm}$ was placed into a $400 \mathrm{~mm}$ stainless steel tubular reactor with a $25 \mathrm{~mm}$ inner diameter. The reactor, connected to air flow, was introduced into a preheated tube furnace. Experiments were realized at reactor temperatures of 700,800 and $900{ }^{\circ} \mathrm{C}$. The term "reactor temperature" in this work indicates the temperature measured by a thermocouple placed near the ceramic wall of the tube surface. Of course, the sample temperature does not immediately reach the value of the furnace temperature. At the beginning of the experiment, the direction of heat flux is from the furnace wall to the sample; however, in later stages, after 
exothermic reactions start, the sample temperature rapidly increases and the heat flux direction can reverse.
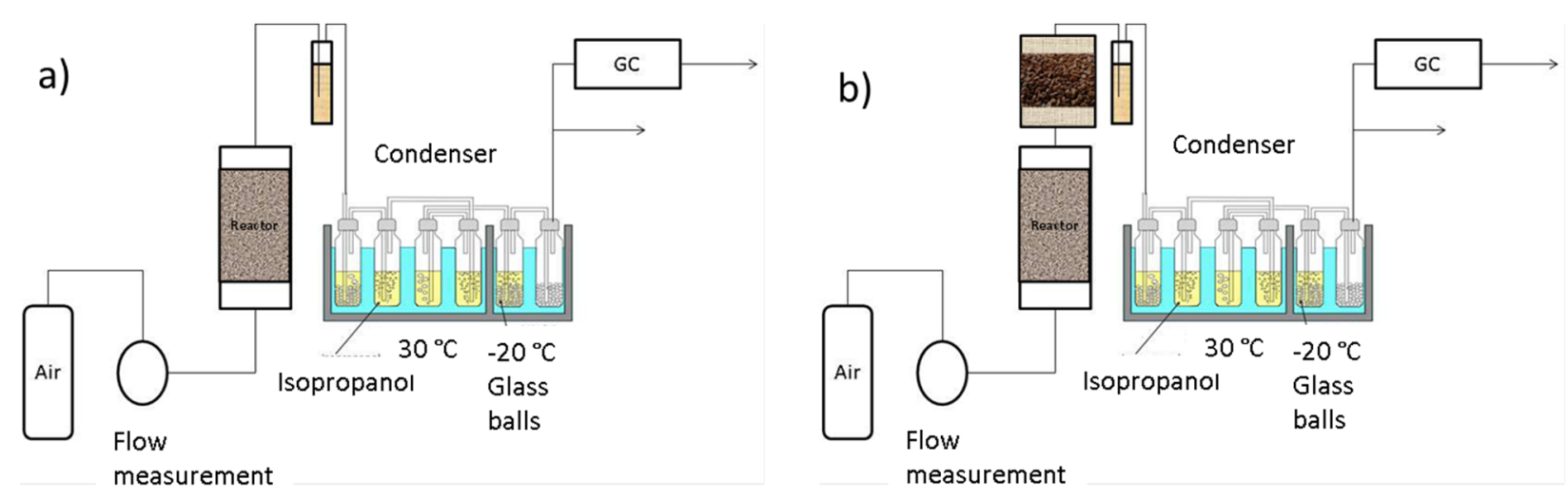

Figure 1. Laboratory scale gasification unit: (a) without secondary catalysis (b) with secondary catalysis.

Compressed air from a bottle was used as the gasification medium. The air flow was continuously recorded and maintained at $15.5 \pm 1.01 . \mathrm{min}^{-1}$. This value of air flow corresponded to the optimum oxygen demand for RDF gasification. The gas leaving the reactor was led to a system of scrubbers filled with isopropanol and in some cases also glass beads, one of which was non-thermostated at room temperature; four scrubbers were thermostated at $30^{\circ} \mathrm{C}$, and two thermostated at $-20^{\circ} \mathrm{C}$ in a cryostat. All scrubbers were weighed before and after each experiment to determine the tar and condensed water yield. The gas leaving the condenser system was fed to a microchromatograph $\left(\mathrm{GCM}^{\circledR}\right.$ Micro Box III microchromatograph, SLS MicroTechnology GmbH, Hamburg, Germany) where the content of the main gaseous components $\left(\mathrm{H}_{2}, \mathrm{CO}, \mathrm{CO}_{2}, \mathrm{CH}_{4}, \mathrm{~N}_{2}\right)$ was determined every $3 \mathrm{~min}$. The duration of the experiment was $1.5 \mathrm{~h}$. During this time, complete conversion of $\mathrm{RDF}$ was reached in all cases. In terms of the gasification reaction, the first $15 \mathrm{~min}$ of each experiment represented the most important period. At each temperature, the experiments were performed three times. For all measured values, the arithmetic mean of all three measurements was considered as the final value. In a second series of experiments, a secondary catalytic reactor with natural red clay containing mainly $\mathrm{SiO}_{2}$ and some amount of $\mathrm{Al}_{2} \mathrm{O}_{3}, \mathrm{Fe}_{2} \mathrm{O}_{3}, \mathrm{CaCO}_{3}, \mathrm{MgCO}_{3}$, calcined at $800{ }^{\circ} \mathrm{C}$ and impregnated with $\mathrm{Ni}$ as the catalyst was installed after the gasification reactor to reduce the tar and wax fraction. This catalyst was characterized in the framework of a previous work [22] by pore structure and specific surface measurements at different stages of preparation, thermogravimetric analysis, elemental analysis, and X-ray diffraction analysis, X-ray fluorescence (XRF) analysis, and scanning electron microscopy (SEM). In addition, in the previous work [23], catalytic activity of the used catalyst was confirmed by cracking of model tar components.

\subsection{Tar and Wax Yield Characterization}

The tar and wax yield was determined using a simple gravimetric method. Isopropanol with tar, water and wax collected in scrubbers was distilled in a vacuum rotary evaporator (Hei-VAP Advantage from Heidolph Instruments $\mathrm{GmbH}$, Schwabach, Germany) at $55^{\circ} \mathrm{C}$ and $10 \mathrm{kPa}$. When the time between two drops of the distillate was longer than $4 \mathrm{~s}$, the distillation was prolonged for another $45 \mathrm{~min}$. The distillation residue was weighted and used to calculate the tar and wax yield.

As shown in Figure 2, the tar and waxes, besides a dissolved phase in isopropanol, created an undissolved solid phase. For the characterization of the tar and wax fraction by gas chromatography-mass spectrometry (GC-MS), this undissolved phase was separated from isopropanol by filtration and analyzed separately. GC-MS analysis was carried out using a GC 7890A gas chromatograph (Agilent Technologies, Wilmington, NC, USA) and a 
mass spectroscope 5975C (Agilent Technologies, Wilmington, USA). Conditions of GC-MS measurements were the same as in a previous work [25].

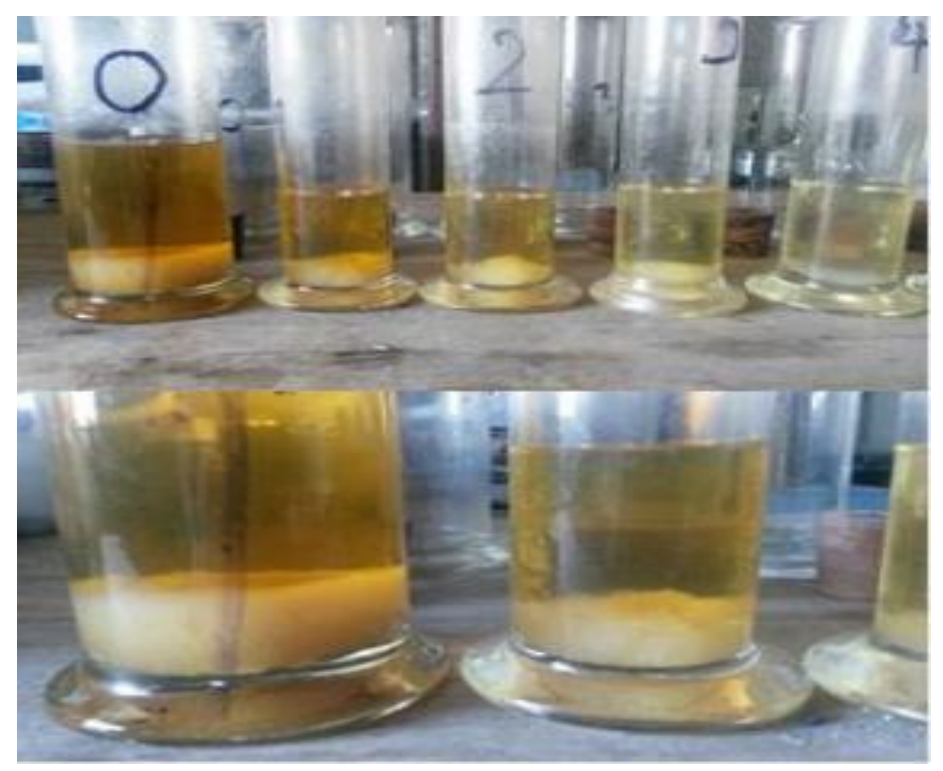

Figure 2. Tar and wax captured in isopropanol.

Nuclear Magnetic Resonance (NMR) spectroscopy was applied for a more detailed characterization of the undissolved fraction. All NMR spectra were acquired using a 600 VNMRS NMR spectrometer (Varian Inc., Palo Alto, Santa Clara, CA, USA) operating at the frequencies of $599.76 \mathrm{MHz}$ for ${ }^{1} \mathrm{H}$ and $150.82 \mathrm{MHz}$ for ${ }^{13} \mathrm{C}$ nuclei. The spectrometer was equipped with a standard tunable $\mathrm{X} / \mathrm{H}$ double-resonance probe, an inverse $\mathrm{HCN}$ tripleresonance probe and a $3.2 \mathrm{~mm}$ magic-angle spinning (MAS) probe. All liquid state NMR spectra $\left({ }^{1} \mathrm{H},{ }^{13} \mathrm{C}\right.$, COSY spectrum with gradient coherence selection, HSQC (Heteronuclear Single Quantum Coherence) and band-selective HMBC (Heteronuclear Multiple Bond Correlation) spectrum with gradient coherence selection) were measured in d6-benzene at $25{ }^{\circ} \mathrm{C}$. The chemical shift axis for solid state was referenced using hexamethylbenzene (132.3 and 17.3 ppm [26,27]). The solid state sample was spun at $7 \mathrm{kHz}$ at room temperature. First, a simple one-pulse experiment was run with a relaxation time of $30 \mathrm{~s}$. After that, a ${ }^{1} \mathrm{H}-{ }^{13} \mathrm{C}$ cross-polarization experiment with spinning sideband suppression was run with linear ramping during a $7 \mathrm{~ms}$ cross-polarization period. For ${ }^{1} \mathrm{H}$ decoupling, the two-pulse phase modulation (TPPM) decoupling scheme was used. All NMR spectra are shown in Figures S1-S9 in the Supplementary Materials to this work (NMR images).

Elemental composition of both dissolved and undissolved fractions of tar and wax was measured by the same method described in Chapter 2.1.

\section{Results and discussion}

\subsection{Results of RDF Characterization}

The course of thermal decomposition of RDF is demonstrated by TG and DSC curves in Figure 3. In an inert environment, four basic thermal decomposition steps were observed. In the temperature range of up to $105^{\circ} \mathrm{C}$, water was evaporated. The second step in the temperature range of 230 to $400{ }^{\circ} \mathrm{C}$ is due to the decomposition of the cellulosic fraction. Plastic fraction represented mainly by polyethylene and polypropylene is decomposed in the temperature range of 400 to $500{ }^{\circ} \mathrm{C}$. A separate thermogravimetric analysis of cellulose and low density polyethylene [28] confirmed these findings. The final decomposition step under an inert atmosphere in the temperature range of 700 to $750{ }^{\circ} \mathrm{C}$ corresponds with the decomposition of inorganic salts such as $\mathrm{CaCO}_{3}$ which are present in the paper fraction. The study on the thermal decomposition of $\mathrm{CaCO}_{3}$ by Singh and Singh [29] shows its 
decomposition at temperatures from 700 to $800{ }^{\circ} \mathrm{C}$. The last decomposition step is the result of char combustion under oxygen. Except for the last combustion steps, all other decomposition steps are endothermic as it results from the DSC curve.

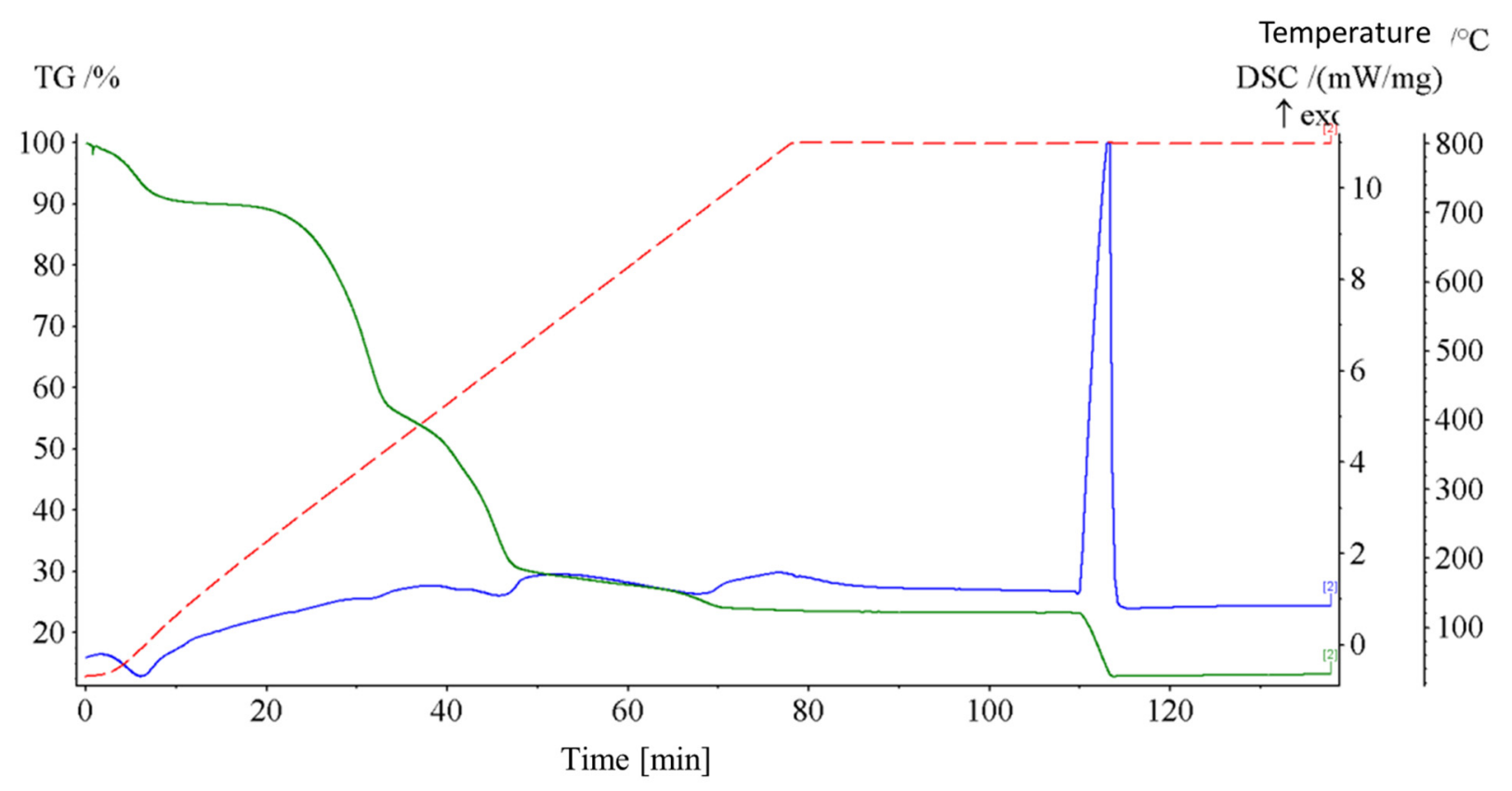

Figure 3. Thermogravimetric record of RDF.

The measured proximate and elemental composition of RDF shown in Table 1 is in relatively good coherence with data from the literature [28,29]. However, the composition of RDF depends on many factors including location and method of production. Sulfur and chlorine content can significantly affect the downstream processes required for gas cleaning. Sulfur content in the studied RDF is lower than in coal. Chlorine content of 0.73 mass \% includes the studied RDF in Class 3 of a scale with three classes defined by European standard EN 15359: 2011. The RDF content of chlorine reported in the literature varies between 0.3 and 0.8 mass $\%$. The studied RDF had relatively high calorific value. The measured higher heating value (HHV) of $20.81 \mathrm{MJ} \cdot \mathrm{kg}^{-1}$ is comparable with the calorific value of sub-bituminous coal.

Table 1. Proximate and elemental composition and calorific value of RDF.

\begin{tabular}{cc}
\hline Proximate composition (wt. \%): & \\
\hline Moisture & 10.00 \\
Volatile matter & 66.25 \\
Fixed carbon & 9.29 \\
Ash & 14.46 \\
\hline Elemental composition (wt. \%): \\
\hline Carbon \\
Hydrogen \\
Nitrogen & 46.47 \\
Sulfur & 6.43 \\
Chlorine & 0.84 \\
Oxygen * & 0.35 \\
HHV (MJ.kg ${ }^{-1}$ ) & 0.73 \\
\hline
\end{tabular}




\subsection{Single Stage RDF Gasification}

In a single-stage batch gasification reactor, the amount of generated gas and its composition are changing. During the reaction of the material under the constant flow of an oxidizing agent, the equivalent ratio (oxygen flow to stoichiometric oxygen requirement) increases. This change in condition results in a change of gas composition. The contents of important combustible components- $\mathrm{H}_{2}, \mathrm{CO}$, and $\mathrm{CH}_{4}-$ change during the process and shows a maximum at a specific point of the process. Figure 4 shows the gas composition change up to $90 \mathrm{~min}$ from the beginning of the process when the reactor temperature was $900{ }^{\circ} \mathrm{C}$. Both $\mathrm{H}_{2}$ and $\mathrm{CO}$ contents show a maximum of around $500 \mathrm{sec}$ after the start of the gasification. Lower concentrations in the initial stage of the experiment were caused by gradual heating of the sample to the required temperature and by starting the gasification reactions. After reaching this maximum ( $24 \mathrm{~mol} . \% \mathrm{H}_{2}$ and $21 \mathrm{~mol} . \% \mathrm{CO}$ ), the content of $\mathrm{H}_{2}$ rapidly decreased to values below $1 \%$ after $35 \mathrm{~min}$ from the beginning of the process. It was assumed that during this period, mainly the volatile fraction of the waste would be gasified. The decrease in the $\mathrm{CO}$ content is not so rapid; it shows relatively high values up to $50 \mathrm{~min}$ after the start of the process. After the gasification of the volatile fraction, gasification of fixed carbon continues; this process is much slower and a longer time is required for total gasification of the char. As the char is consumed in the reactor, the content of $\mathrm{CO}$ decreases and the content of $\mathrm{CO}_{2}$ starts to increase again. The maximum content of $\mathrm{CH}_{4}$ and $\mathrm{CO}_{2}$ was recorded at around 350 sec from the process beginning; then the content of $\mathrm{CH}_{4}$ decreased below $1 \%$ and that of $\mathrm{CO}_{2}$ to around $3 \%$ in the following minutes. However, by increasing the equivalent ratio above a critical value, the $\mathrm{CO}_{2}$ content started to increase again while the $\mathrm{CO}$ content decreases. The course of gas composition can be influenced by the composition of feed as well as by the flow of oxidizing agent (air in this case). In this work, the air flow rate was maintained at $15.5 \pm 1.01 \mathrm{~min}^{-1}$.

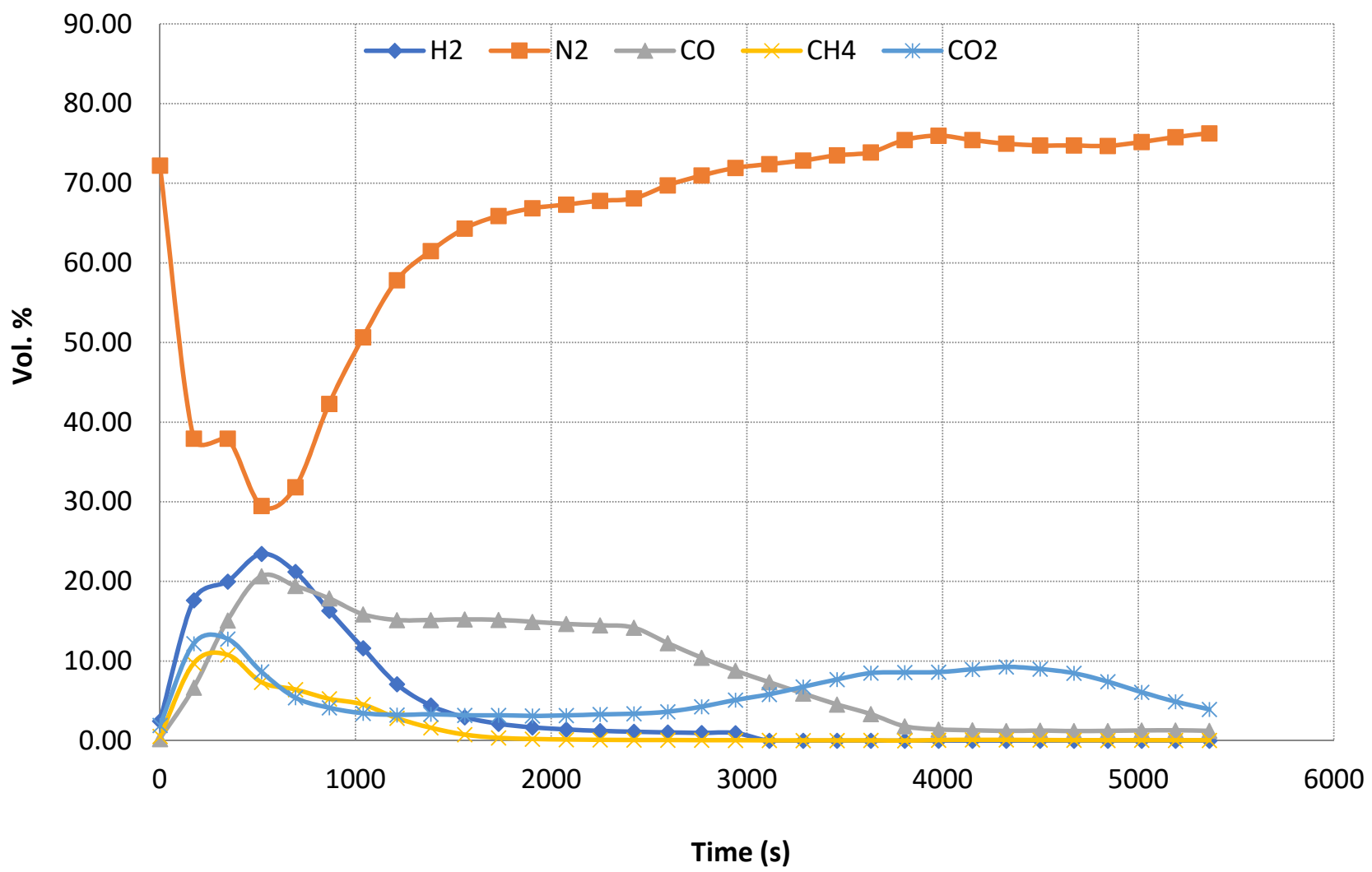

Figure 4. Time dependence of gas composition at $900{ }^{\circ} \mathrm{C}$.

Reactor temperature showed significant influence on product yields and gas composition. Table 2 shows product yields at all three reactor temperatures selected in this work. 
Gas released from the reactor originated from sample gasification and from air introduced to the reactor. The gas product yields in Table 2 were calculated by differences between the mass of the sample and the mass of other products. Thus, the mass of air introduced to the system is not included but only the portion of the sample transformed to gas product. By increasing the temperature, both tar and wax and aqueous yields decreased. However, waxes captured in isopropanol were visible as a solid phase at all temperatures (Figure 2). The mass yield of RDF transformed to syngas increased from 0.46 at $700{ }^{\circ} \mathrm{C}$ to 0.67 at $900{ }^{\circ} \mathrm{C}$. At $700{ }^{\circ} \mathrm{C}$, a slightly higher ash yield was recorded, which indicates lower carbon conversion at this temperature.

Table 2. Product mass yields of single-stage batch gasification of RDF [kg/kg RDF].

\begin{tabular}{cccc}
\hline Temperature $\left({ }^{\circ} \mathrm{C}\right)$ & 700 & 800 & 900 \\
Gas ${ }^{\text {a }}$ & 0.46 & 0.63 & 0.67 \\
Tar and Wax & 0.1 & 0.08 & 0.06 \\
Aqueous & 0.25 & 0.13 & 0.10 \\
Ash & 0.19 & 0.16 & 0.17 \\
\hline a calculated by difference between mass of the sample and mass of other products. (mass of added air is excluded).
\end{tabular}

For the used RDF and air flow rate, the maximum content of $\mathrm{H}_{2}$ and $\mathrm{CO}$ at all temperatures was measured around $500 \mathrm{sec}$ after the process start. Table 3 shows the gas composition at this point for all reactor temperatures. The maximum content of $\mathrm{H}_{2}, \mathrm{CO}$, and $\mathrm{CH}_{4}$ increased from $10.5,8.5$ and $6.5 \mathrm{~mol} \%$ at $700{ }^{\circ} \mathrm{C}$ to $20,16.5$ and $9 \mathrm{~mol} \%$. at 900 ${ }^{\circ} \mathrm{C}$, respectively. The $\mathrm{CO}_{2}$ content decreased from $21.5 \mathrm{~mol} \%$ at $700{ }^{\circ} \mathrm{C}$ to $14.5 \mathrm{~mol} \%$ at 900 ${ }^{\circ} \mathrm{C}$. The decrease in the mole fraction of nitrogen is a result of the increasing amount of $\mathrm{H}_{2}$, $\mathrm{CO}$, and $\mathrm{CH}_{4}$ since the amount of nitrogen was practically constant.

Table 3. Gas composition (mol. \%) at $500 \mathrm{~s}$.

\begin{tabular}{cccccc}
\hline Temperature $\left({ }^{\circ} \mathbf{C}\right)$ & $\mathbf{H}_{\mathbf{2}}$ & $\mathbf{N}_{\mathbf{2}}$ & $\mathbf{C O}$ & $\mathbf{C H}_{\mathbf{4}}$ & $\mathbf{C O}_{\mathbf{2}}$ \\
\hline 700 & 10.5 & 51.5 & 8.5 & 6.5 & 21.5 \\
800 & 16 & 45 & 7.5 & 9.5 & 18 \\
900 & 20 & 36.5 & 16.5 & 9 & 14.5 \\
\hline
\end{tabular}

\subsection{Tar and Wax Yield Characterization}

To determine the nature of undissolved solid phase, GC-MS analysis was performed separately for every phase. As shown in Table 4, the Pyro-GC-MS analysis of undissolved phase identified mainly $C_{5}-C_{12}$ alkenes, which indicates that the undissolved solid phase captured in isopropanol is formed by segments of polyolefin chains. Formation of this phase can be considered as the main disadvantage of a simple one-stage non-catalytic fixedbed or semi-batch gasification system. Such heavy tar and wax fraction can cause major fouling problems in downstream devices installed next to the reactor. GC-MS analysis of the dissolved phase identified ethanol, aliphatic and aromatic hydrocarbons and traces of many oxygenated compounds.

Nuclear magnetic resonance confirmed the nature of the solid undissolved phase as segments of polymer chains. All NMR spectra are shown in the Supplementary Materials to this work (NMR images), particularly the ${ }^{1} \mathrm{H}$ spectrum (Figure S1), ${ }^{13} \mathrm{C}$ (Figure S2), 2D COSY (Figures S3 and S4), 2D HSQC (Figures S5 and S6), 2D HMBC (Figure S7), directly measured ${ }^{13} \mathrm{C}$ MAS spectrum (Figure S8) and the ${ }^{13} \mathrm{C}$ MAS spectrum with the utilization of ${ }^{1} \mathrm{H}-{ }^{13} \mathrm{C}$ cross-polarization (Figure S9). Both liquid- and solid-state NMR revealed dominant content of linear and branched alkyl chains. A small amount of molecules with terminal double-bond moieties were also observed in the liquid state. 2D correlation NMR spectra (especially multiple bond correlations in the HMBC spectrum) indicated the presence of polyethylene and polypropylene chains. A very good correlation with the literature was found for the relative chemical shifts of polyethylene signals in [30] measured at $110{ }^{\circ} \mathrm{C}$. 
Table 4. GC-MS analysis.

\begin{tabular}{cccc}
\hline \multicolumn{2}{c}{ Undissolved Phase } & \multicolumn{2}{c}{ Dissolved Phase } \\
\hline Component & Peak Area (\%) & Component & Peak Area (\%) \\
\hline Pentene & 15.08 & Isopropanol & 93.87 \\
Hexene & 14.8 & Ethanol & 1.15 \\
Heptene & 11 & Dimethylbenzene & 0.37 \\
Octene & 7.56 & Nonadecene & 0.18 \\
Dimethylbenzene & 6.42 & Octadecene & 0.11 \\
Cyclodecane & 5.64 & Hexadecane & 0.09 \\
Toluene & 4.71 & Tetradecane & 0.09 \\
Hexadiene & 4.15 & Tetradecene & 0.08 \\
Dodecene & 2.91 & Benzene & 0.08 \\
Nonene & 2.59 & Pentdecene & 0.08 \\
\hline
\end{tabular}

\subsection{Effect of Secondary Catalysis on the Tar and Wax Yield}

A natural clay catalyst doped with $\mathrm{Ni}$ was employed in a secondary reactor to reduce the yield of tar and wax in the produced gas. The clay containing mainly $\mathrm{SiO}_{2}$ and some amount of $\mathrm{Al}_{2} \mathrm{O}_{3}, \mathrm{Fe}_{2} \mathrm{O}_{3}, \mathrm{CaCO}_{3}, \mathrm{MgCO}_{3}$, etc. [31] had the initial specific surface area of approximately $100 \mathrm{~m}^{2} \mathrm{~g}^{-1}$; however, its surface area decreased by calcination to $35 \mathrm{~m}^{2} \mathrm{~g}^{-1}$. Details of the two-stage RDF gasification with a clay catalyst in the secondary reactor were published in a previous work [22]. Here, we focus on the effect of the secondary catalyst on the tar and wax yield only. Figure 5 shows tar fraction captured in isopropanol after the secondary catalytic stage. A comparison of this picture with Figure 2 shows a significant visible effect of secondary catalysis on the tar and wax yield. After installing the catalytic stage, no solid fraction was captured in isopropanol and the used isopropanol had a clearer color.

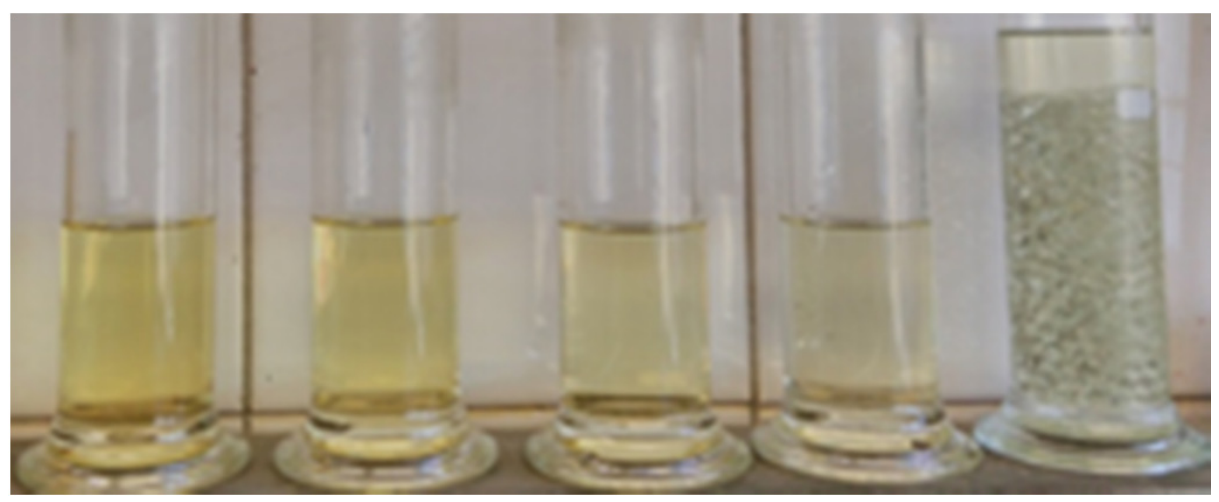

Figure 5. Tar and wax captured in isopropanol after installing a secondary catalytic reactor.

A comparison of tar yields of a two stage catalytic system with a system without a catalyst (data from Table 2) shown in Figure 6a proved that Ni-impregnated clay reduced the tar and wax yield by up to $91.8 \%$. The effect of the Ni-based catalyst on the removal of tar from waste and biomass gasification was confirmed also by other authors [32,33]. Furthermore, the influence of the temperature in the catalytic process is significant, as can be seen in Figure $6 \mathrm{~b}$ ( $\mathrm{Y}$ axis zoom in); an increase in the temperature from $700{ }^{\circ} \mathrm{C}$ to $900{ }^{\circ} \mathrm{C}$ decreased the tar yield by around $45 \%$. Compared to the simple one-stage semi-batch gasification, no wax fraction in the form of a solid phase in isopropanol was observed in the two-stage catalytic system. High molecular weight polymer segments in the gasifier product can have an extremely negative effect on the downstream processing of the generated gas; therefore, simple one-stage semi-batch gasification of RDF is not recommended. 
a)

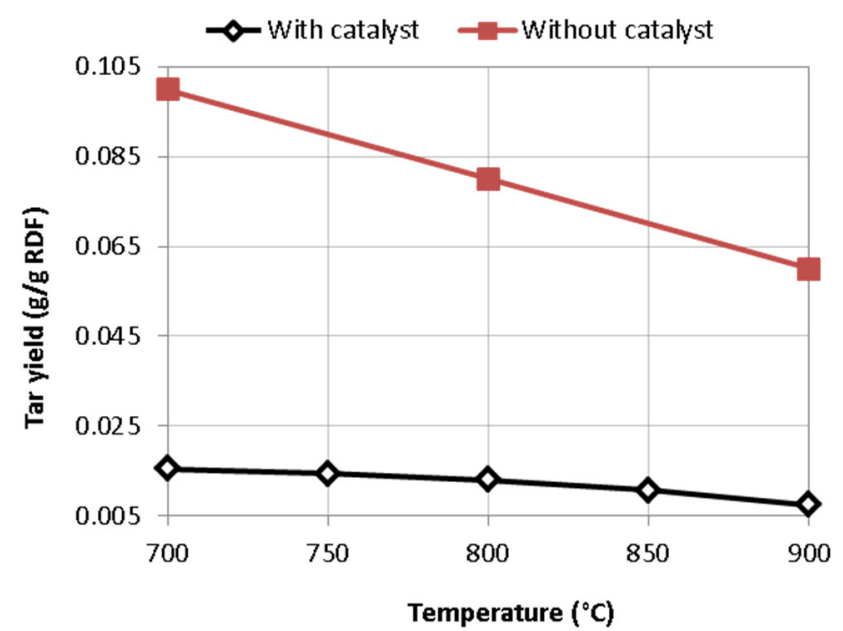

b)

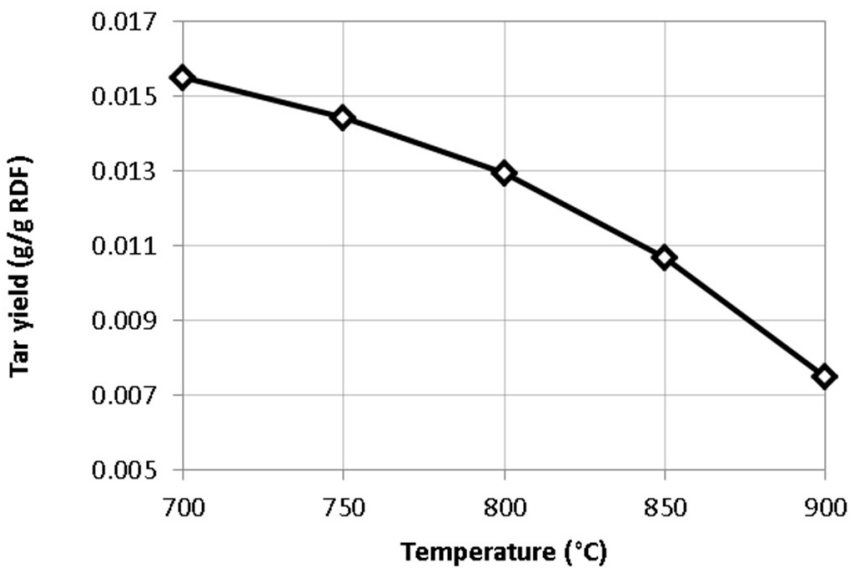

Figure 6. Tar yield from RDF gasification with a secondary catalytic stage with Ni-doped clay catalyst. (a) Comparison with non catalytic process, (b) Effect of temperature.

\section{Conclusions}

A single-stage semi-batch gasification of RDF can provide a relatively high yield of heavy tars and waxes. The tar and wax fraction can amount to up to $10 \%$ of the feed mass. Since high tar content gas has extremely negative effect on downstream processing, simple one-stage semi-batch gasification of RDF is not recommended. GC-MS and NMR analysis have shown that wax fraction captured in the form of a solid powder in isopropanol consists mainly of polyethylene and polypropylene chains. The nature of the waxes proves that they come from the plastic fraction of RDF and further thermal and catalytic processing can lead to their total decomposition. The content of most important gas components changes during the process; for the used RDF and air flow rate, the maximum content of $\mathrm{H}_{2}$ and $\mathrm{CO}$ at all temperatures was measured around $500 \mathrm{sec}$ after the start of the process. The maximum content of $\mathrm{H}_{2}$ and $\mathrm{CO}$ varied from 10.5 and 8.5 vol. $\%$ at $700{ }^{\circ} \mathrm{C}$ to 20 and 16.5 vol. $\%$ at $900{ }^{\circ} \mathrm{C}$, respectively. Calcined red clay can serve as a low-cost catalyst in the removal of tar and waxes from the gas. Impregnation of these catalysts with $\mathrm{Ni}$ leads to better tar removal and a higher content of $\mathrm{H}_{2}$ in the gas; however, it can also represent additional costs related to catalyst preparation and after use treatment. Full commercialization of MSW gasification requires further investigation of thermo-catalytic thermal decomposition and downstream gas purification processes.

Supplementary Materials: The following are available online at https:/ / www.mdpi.com/2227-971 7/9/2/343/s1: Figure S1. Aliphatic part of the liquid state ${ }^{1} \mathrm{H}$ NMR spectrum. Figure S2. Aliphatic part of the liquid state ${ }^{13} \mathrm{C}$ NMR spectrum. Figure S3. 2D COSY NMR spectrum of the liquid state sample. Figure S4. Homonuclear correlations of aliphatic protons in a zoom of the 2D COSY NMR spectrum of the liquid state sample. Figure S5. 2D HSQC NMR spectrum from the aliphatic chemical shift regions of ${ }^{1} \mathrm{H}$ and ${ }^{13} \mathrm{C}$. Figure S6. 2D HSQC NMR spectrum from the double-bond chemical shift regions of ${ }^{1} \mathrm{H}$ and ${ }^{13} \mathrm{C}$. Figure S7. Band-selective gHMBC NMR spectrum from the aliphatic chemical shift regions of ${ }^{1} \mathrm{H}$ and ${ }^{13} \mathrm{C}$. Figure S8. Directly measured solid-state magic-angle spinning (7 kHz spin rate) ${ }^{13} \mathrm{C}$ NMR spectrum of the sample. Figure S9. Solid-state magic-angle spinning (7 kHz spin rate) ${ }^{13} \mathrm{C}$ NMR spectrum with ${ }^{1} \mathrm{H}-{ }^{13} \mathrm{C}$ cross-polarization

Author Contributions: Conceptualization, J.H.; Formal analysis, J.H.; Funding acquisition, J.H.; Investigation, J.H., P.Š. and M.Š.; Methodology, J.H., P.Š. and M.Š.; Project administration, J.H.; Supervision, J.H.; Writing—original draft, J.H.; Writing—review \& editing, P.Š. and M.Š. All authors have read and agreed to the published version of the manuscript. 
Funding: This research was funded by Slovak Research and Development Agency, Grant APVV-150148 and Grant APVV-19-0170.

Institutional Review Board Statement: Not applicable.

Informed Consent Statement: Not applicable.

Data Availability Statement: Data are contained within the article or Supplementary Materials.

Acknowledgments: In this work we used equipment obtained under the OP Research and Development project ITMS 26240220084, co-financed by the Fund of European Regional Development to whom we express our thanks.

Conflicts of Interest: The authors declare no conflict of interest.

\section{References}

1. European Parliament. DIRECTIVE (EU) 2018/850 of the European parliament and of the council of 30 May 2018 , amending Directive 1999/31/EC on the landfill of waste. Off. J. Eur. Union I 2018, 150, 100-108.

2. Rudra, S.; Tesfagaber, Y.K. Future district heating plant integrated with municipal solid waste (MSW) gasification for hydrogen production. Energy 2019, 180, 881-892. [CrossRef]

3. Pio, D.T.; Tarelho, L.A.C.; Tavares, A.M.A.; Silva, V. Co-gasification of refused derived fuel and biomass in a pilot-scale bubbling fluidized bed reactor. Energy Convers. Manag. 2020, 206, 112476. [CrossRef]

4. Antoniou, A.; Stravropoulus, G.; Zabaniotou, A. Activation of end of life tyres pyrolytic char for enhancing viabiliy of pyrolysisCritical review, analysis and recommendations for a hybrid dual system. Renew. Sustain. Energy Rev. 2014, 39, 1053-1073. [CrossRef]

5. Haydary, J. Modelling of two stage gasification of waste biomass. Chem. Eng. Trans. 2017, 61, 1465-1470. [CrossRef]

6. Holmgren, K.M.; Berntsson, T.; Andersson, E.; Rydberg, T. System aspects of biomass gasification with methanol synthesisProcess concepts and energy analysis. Energy 2012, 45, 817-828. [CrossRef]

7. Tsubouchi, N.; Mochizuki, Y.; Wang, Y.; Ohtsuka, Y. Fate of the Chlorine in Coal in the Heating Process. ISIJ Int. 2018, 58, 227-235. [CrossRef]

8. Mangena, S.; Bunt, J.; Waanders, F. Physical property behaviour of North Dakota lignite in an oxygen/steam blown moving bed gasifier. Fuel Process. Technol. 2013, 106, 326-331. [CrossRef]

9. Li, G.; Zhang, K.; Yang, B.; Liu, F.; Weng, Y.; Liu, Z.; Fang, Y. Life cycle analysis of a coal to hydrogen process based on ash agglomerating fluidized bed gasification. Energy 2019, 174, 638-646. [CrossRef]

10. Abaimov, N.A.; Butakov, E.B.; Burdukov, A.P.; Osipov, P.V.; Ryzhkov, A.F. Investigation of air-blown two-stage entrained-flow gasification of micronized coal. Fuel 2020, 271, 117487. [CrossRef]

11. Beenackers, A.A.C.M. Biomass gasification in moving beds, a review of European technologies. Renew. Energy 1999, 16, 1-4. [CrossRef]

12. Campoy, M.; Gómez-Barea, A.; Ollera, P.; Nilsson, S. Gasification of wastes in a polit fluidized bed gasifier. Fuel Process. Technol. 2014, 121, 63-69. [CrossRef]

13. Park, J.; Lee, Y.; Ryu, C. Reduction of primary tar vapor from biomass by hot char particles in fixed bed gasification. Biomass Bioenergy 2016, 90, 114-121. [CrossRef]

14. Yu, H.; Zhang, Z.; Li, Z.; Chen, D. Characteristics of tar formation during cellulose, hemicellulose and lignin gasification. Fuel 2014, 118, 250-256. [CrossRef]

15. Li, C.; Suzuki, K. Tar property, analysis, reforming mechanism and model for biomass gasification-An overview. Renew. Sustain. Energy Rev. 2009, 13, 594-604. [CrossRef]

16. Lopez, G.; Artetxe, M.; Amutio, M.; Alvarez, J.; Bilbao, J.; Olazar, M. Recent advances in the gasification of waste plastics. A critical overview. Renew. Sustain. Energy Rev. 2018, 82, 576-596. [CrossRef]

17. Wilk, V.; Hofbauer, H. Conversion of mixed plastic wastes in a dual fluidized bed steam gasifier. Fuel 2013, 107, 787-799. [CrossRef]

18. Al-Salem, S.M.; Yang, Y.; Wang, J.; Leeke, G.A. Pyro-Oil and Wax Recovery from Reclaimed Plastic Waste in a Continuous Auger Pyrolysis Reactor. Energies 2020, 13, 2040. [CrossRef]

19. Buah, W.; Cunliffe, A.; Williams, P. Characterization of Products from the Pyrolysis of Municipal Solid Waste. Process. Saf. Environ. Prot. 2007, 85, 450-457. [CrossRef]

20. Arabiourrutia, M.; Elordi, G.; Lopez, G.; Borsella, E.; Bilbao, J.; Olazar, M. Characterization of the waxes obtained by the pyrolysis of polyolefin plastics in a conical spouted bed reactor. J. Anal. Appl. Pyrolysis 2012, 94, 230-237. [CrossRef]

21. Singh, R.N.; Singh, S.P.; Balwanshi, J.B. Tar removal from producer gas: A review. Res. J. Eng. Sci. 2014, 3, 16-22.

22. Šuhaj, P.; Haydary, J.; Husár, J.; Steltenpohl, P.; Šupa, I. Catalytic gasification of refuse-derived fuel in a two-stage laboratory scale pyrolysis/gasification unit with catalyst based on clay minerals. Waste Manag. 2019, 85, 1-10. [CrossRef]

23. Steltenpohl, P.; Husár, J.; Šuhaj, P.; Haydary, J. Performance of Catalysts of Different Nature in Model Tar Component Decomposition. Catalysts 2019, 9, 894. [CrossRef] 
24. Husár, J.; Haydary, J.; Šuhaj, P.; Steltenpohl, P. Potential of tire pyrolysis char as tar-cracking catalyst in solid waste and biomass gasification. Chem. Pap. 2019, 73, 2091-2101. [CrossRef]

25. Mandal, S.; Bhattacharya, T.K.; Verma, A.K.; Haydary, J. Optimization of process parameters for bio-oil synthesis from pine needles (Pinus roxburghii) using response surface methodology. Chem. Pap. 2018, 72, 603-616. [CrossRef]

26. Webb, G.A. Modern Magnetic Resonance; Springer: Dordrecht, The Netherlands, 2006.

27. Mittal, K.L. Silanes and Other Coupling Agents; Leiden: Boston, MA, USA, 2009; Volume 5.

28. Xiang, Z.; Liang, J.; Morgan, H.M., Jr.; Liu, Y.; Mao, H.; Bu, Q. Thermal behavior and kinetic study for co-pyrolysis of lignocellulosic biomass with polyethylene over Cobalt modified ZSM-5 catalyst by thermogravimetric analysis. Bioresour. Technol. 2018, 247, 804-811. [CrossRef]

29. Singh, N.B.; Singh, N.P. Formation of $\mathrm{CaO}$ from thermal decomposition of calcium carbonate in the presence of carboxylic acids. J. Therm. Anal. Calorim. 2007, 89, 159-162. [CrossRef]

30. Mehta, A.; Tembe, G.; Parikh, P.; Mehta, G. A study pf ethylene polymerization catalyzed by homogenous and silsesquioxane supported Titanium(IV)complexes. Polymers 2013, 58, 875-882. [CrossRef]

31. Haydary, J.; Susa, D.; Dudáš, J. Pyrolysis of aseptic packages (tetrapak) in a laboratory screw type reactor and secondary thermal/catalytic tar decomposition. Waste Manag. 2013, 33, 1136-1141. [CrossRef]

32. Baker, E.G.; Mudge, L.K.; Brown, M.D. Steam gasification of biomass with nickel secondary catalysts. Ind. Eng. Chem. Res. 1987, 26, 1335-1339. [CrossRef]

33. Wang, J.; Cheng, G.; You, Y.; Xiao, B.; Liu, S.; He, P.; Guo, D.; Guo, X.; Zhang, G. Hydrogen-rich gas production by steam gasification of municipal solid waste (MSW) using NiO supported on modified dolomite. Int. J. Hydrogen Energy 2012, 37, 6503-6510. [CrossRef] 